\title{
Study on the Sentiment Polarity Types of Collocations for too and very
}

\author{
By Mohamed Yassine Frej ${ }^{*}$ \\ Jeesun $\mathrm{Nam}^{\dagger}$
}

\begin{abstract}
This study is a corpus-based approach conducted to compare the two amplifiers too and very in terms of what sentiment polarity types can be attributed to the words in collocation with these adverbs. These adverbs are generally known as intensifying a given meaning of modified words, notably adjectives, verbs or nouns. However, based on the empirical examination of the British National Corpus $(B N C)$, we assume that the prominent sentiment polarity type of the words collocated with very is dissimilar to that of the words collocated with too. For instance, while the adjectives collocated with very expresses rather a positive sentiment polarity like in 'The soup is very tasty', those appeared with too mostly express a negative sentiment polarity like in 'This car is too expensive'. In most previous works, it is asserted that it is due to the particular semantic function of the adverb too, since no matter what semantic types of adjectives are, the sequences such as too small, too bright or too young express a negative evaluation. Nevertheless, we advocate that this interpretation does not result from the special function of too, but from the semantic orientation itself of the words collocated with these adverbs. The experiment we performed in this study reveals that the adjectives of negative polarity co-occur with too 7 times more frequently than those of positive polarity. On the contrary, the adjectives of positive polarity co-occur with very 2.6 times more frequently than those of negative polarity. The distribution of part-of-speech in the position collocated with these adverbs, the proportion of words with positive/negative/neutral polarity and the corpus types such as formal/written texts or informal/spoken texts are discussed as well, to clarify the empirical differences of these adverbs.
\end{abstract}

\section{Introduction}

This study is a corpus-based approach conducted to compare the two amplifiers too and very in terms of what sentiment polarity types can be attributed to the words in collocation with these adverbs. In human languages,

${ }^{*}$ DICORA Researcher, DICORA/ Hankuk University of Foreign Studies, Korea.

${ }^{\dagger}$ Full Professor, DICORA/ Hankuk University of Foreign Studies, Korea. 
more can be learned about the differences between certain words through the words they collocate with. The latter are referred to, in the literature, as collocations. Firth (1957) emphasized the importance of both linguistic and situational contexts for the description of human languages. "You shall know a word by the company it keeps." (ibid: 195).

The abundance of large collections of spoken and written corpora in electronic form and the possibility to investigate those texts made by the development of technologies in corpus linguistics over the last years laid the path towards better understanding of how words are arranged in languages. Thus, the nature of vocabulary and its contribution to the existing semantics and syntax-based theories are reconsidered now.

Adverbs of degree and their collocations have been extensively examined in the literature. One of the first studies is Quirk et al (1985). The framework used was essentially a semantic one, by which amplifiers also called intensifiers, such as absolutely, completely, really and very, were considered to express degrees of increasing intensity, whereas downtoners, such as rather, a bit, somewhat and quite, were considered as scaling the sense of an adjective downward from an assumed norm, often used as a softening device in cases where the adjective sounds too strong when left unmodified.

Based on a large (40-million words) corpus of American and British spoken and written English is another important corpus-based study of amplifier-adjective by Biber, Johansson, Leech, Conrad, and Finegan's (1999). The description shows that the most frequent amplifiers immediately preceding adjectives in British English conversation are very, so, really, and too followed by absolutely, bloody, damn, real, completely, and totally. In American English conversational genres, the distribution is similar, except for bloody, which is infrequent, and real, which is much more frequent than in British English. Extremely, highly, entirely, fully, incredibly, perfectly, strongly, and terribly also occur frequently in both regional varieties, especially in written, academic genres. Biber et al. (1999, p. 545) show that the most frequent amplifieradjective collocations in British English conversation are very good, very nice, really good, really nice, and too bad, whereas in American English conversation really good, too bad, very good, real good, real quick, really bad, really nice, too big, and very nice are the most frequent. Also, they suggested that they somewhat tend to be used interchangeably in certain contexts despite their different meanings. The suggestions of this study are interesting and need to be speculated using a different corpus.

Due to the growing interest in sentiment analysis of online reviews people write for all types of products and services, a huge amount of work has been devoted to the analysis of subjective expressions. Recent research focuses on assigning a polarity such as positive or negative to subjective expressions (i.e. adjectives, adverbs, verbs...) which contain opinions, emotions or sentiments. Although those subjective expressions are indispensable to determine the sentiment polarity of utterances, the overall sentiment polarity of sentences might be affected by another type of device referred to as polarity shifting markers. Negation markers such as not are one type of those polarity shifting 
markers (Kennedy \& Inkpen 2006). For example, in the sentence the car is not comfortable, the polarity of the word comfortable is positive, whereas the polarity of the whole sentence is reversed because of the negation marker not. In fact, valence shifters (Polanyi \& Zaenen, 2004), the terms that can change the semantic orientation of another term such as negation, should be taken into consideration. Among diverse valence shifters the authors suggested, negatives and intensifiers seem to be the most obvious shifters, and thus Kennedy \& Inkpen (2006) took these particular devices into account in order to improve the accuracy of their sentiment classification system. However, we advocate in this paper that, unlike negation markers, only few of the occurrences of intensifiers like too and very are used as valence shifters, and that even when those intensifiers exist in sentences conveying a negative evaluation, this evaluation does not result from the special function of too or very, but from the semantic orientation itself of the words collocated with these adverbs. Moreover, not much attention has been given to uncover how those intensifiers are different from each other, and what contexts are required so that the interpretation of the adverb is determined. Therefore, the distribution of partof-speech in the position collocated with these adverbs, the proportion of words with positive/negative/neutral polarity and the corpus types such as formal/written texts or informal/spoken texts are discussed as well, to clarify the empirical differences of these adverbs.

\section{Method}

The BNC (Leech, Rayson \& Wilson, 2001) is a 100-million-word structured collection of spoken and written texts. The corpus was compiled by a consortium of universities, publishers, and the British government in the 1990s to be representative of the spoken and written English used in Britain at the end of the $20^{\text {th }}$ century. The BNC includes 90 million words of written English from eight genres and 10 million words of spoken English from four social class groupings, collected in 38 locations in the United Kingdom. Therefore, the BNC was chosen because of its considerable size and also because it incorporates a robust grammatical tagger which facilitates the retrieval and analysis of words.

Adjectives associated with the amplifiers (too and very) were the focus of the present study. Very and too were selected largely because they are among the most frequent amplifiers in the corpus respectively (see table 1).

Table 1. Frequency of Too/Very in the BNC

\begin{tabular}{ccl}
\hline & Very & Too \\
Frequency & 119,572 & 67,004 \\
\hline
\end{tabular}

Are these highly frequent adverbs similar or different from each other in contributing to sentiment polarity? How often do they express a negative opinion? What kind of collocations are they associated with? To answer these 
questions, we shall examine the part of speech (POS) types that occurred in the right context of very and too in the BNC corpus as well as the evaluation types of these intensifiers in this corpus.

\section{Analysis}

\section{POS Collocation Types}

What we first notice from the occurrences in the table above is that the adverbs under study tend to be associated with a given POS more than another. This is shown clearly in the table below:

Table 3. POS Distribution of the Collocations of Too/Very

\begin{tabular}{ccc}
\hline & too & very \\
adjective & $78 \%$ & $81 \%$ \\
adverb & $10 \%$ & $10 \%$ \\
verb & $7 \%$ & $2 \%$ \\
determiner & $5 \%$ & $7 \%$ \\
\hline
\end{tabular}

As one can see, too and very are primarily associated with adjectives that represent $78 \%$ and $81 \%$ of their collocations respectively. However, the right tokens of too and very are not always the units modified by the adverb. Sometimes, the adverb modifies the second token in its right contexts, not the first one. Nonetheless, when the right context is an adjective or a verb, it is the one modified by the adverb without exception: when a determiner or an adverb appears in the right contexts of too and very, it is not always a modified one, but the unit following the first one can be the unit modified by the adverbs. Therefore, we focus in this study only on the adjectival collocations of too and very to investigate the evaluation types of these adverbs.

For more accurate results, the first 100 collocations were extracted for every adverb. Also, collocations with less than 3 occurrences were excluded. Because of space limitations the table below displays only the first 50 occurrences.

Table 2.50 Strongest Collocations with our Selected Adverbs in the BNC

\begin{tabular}{cccc}
\hline very & frequency & too & Freq. \\
Difficult & 2286 & Far & 3275 \\
indeed & 1939 & Late & 2319 \\
Nice & 1669 & Bad & 787 \\
Thank & 1654 & Busy & 558 \\
Quickly & 970 & Fast & 508 \\
carefully & 601 & Expensive & 388 \\
pleased & 593 & Tired & 279 \\
careful & 503 & Weak & 246 \\
attractive & 416 & Frightened & 122 \\
helpful & 394 & Scared & 95 \\
sad & 327 & Painful & 92 \\
keen & 326 & Embarrassed & 81 \\
\hline
\end{tabular}




\begin{tabular}{|c|c|c|c|}
\hline clever & 322 & Costly & 77 \\
\hline pleasant & 314 & Risky & 69 \\
\hline grateful & 286 & Shy & 63 \\
\hline proud & 273 & Lazy & 62 \\
\hline fond & 219 & Preoccupied & 59 \\
\hline disappointed & 175 & loudly & 52 \\
\hline nicely & 131 & Polite & 52 \\
\hline seldom & 121 & Simplistic & 48 \\
\hline enjoyable & 107 & Restrictive & 45 \\
\hline poorly & 89 & Little & 37 \\
\hline supportive & 77 & Cumbersome & 35 \\
\hline frustrating & 71 & Lenient & 34 \\
\hline talented & 71 & Sexy & 33 \\
\hline distressed & 64 & Inexperienced & 32 \\
\hline amusing & 63 & Hasty & 27 \\
\hline rewarding & 57 & Complacent & 22 \\
\hline distressing & 45 & dwell & 22 \\
\hline tiring & 43 & Greedy & 22 \\
\hline cheaply & 42 & Fussy & 21 \\
\hline good-looking & 41 & Inflexible & 20 \\
\hline windy & 37 & Harshly & 19 \\
\hline time-consuming & 32 & hassle & 17 \\
\hline tasty & 31 & Pessimistic & 16 \\
\hline knowledgeable & 28 & Timid & 15 \\
\hline flattering & 27 & Juicy & 15 \\
\hline stressful & 27 & Bulky & 15 \\
\hline considerate & 21 & oblige & 14 \\
\hline astute & 19 & Engrossed & 13 \\
\hline creditable & 18 & Lax & 12 \\
\hline possessive & 17 & Fanciful & 11 \\
\hline gratifying & 16 & Glib & 11 \\
\hline sketchy & 15 & One-sided & 11 \\
\hline likeable & 15 & Intrusive & 10 \\
\hline obliging & 15 & Pushy & 10 \\
\hline low-key & 15 & Far-fetched & 10 \\
\hline sociable & 15 & Imprecise & 10 \\
\hline anithesis & 15 & Unwieldy & 9 \\
\hline fine-grained & 14 & Uptight & 9 \\
\hline undemanding & 14 & Sanguine & 9 \\
\hline talkative & 13 & Single-minded & 9 \\
\hline commendable & 13 & Inquisitive & 8 \\
\hline approachable & 12 & Obtrusive & 8 \\
\hline touchy & 11 & Easy-going & 8 \\
\hline choosy & 10 & cocky & 8 \\
\hline
\end{tabular}

Polarity Types

In an attempt to investigate how the adverbs analyzed in this study contribute to the polarity of meaning, we classified their collocations as being negative, positive or neutral. The results were as follows: 
Table 5. Polarity of the Collocations of too and very

\begin{tabular}{cccc} 
& positive & negative & neutral \\
too & $12 \%$ & $84 \%$ & $4 \%$ \\
very & $72 \%$ & $20 \%$ & $8 \%$ \\
\hline
\end{tabular}

In the case of very, the $72 \%$ of the adjectives collocated with very are positive adjectives such as nice, pleased, or careful, while only $20 \%$ are negative adjectives such as sad, disappointed, or time-consuming.

Too, on the contrary, is primarily associated with negative adjectives (84\%), examples of collocations are bad, tired, or expensive. Only $12 \%$ of the collocations are positive adjectives such as fast or polite. In other words, the adjectives of negative polarity co-occur with too 7 times more frequently than those of positive polarity. On the contrary, the adjectives of positive polarity co-occur with very 2.6 times more frequently than those of negative polarity. This is the reason why, the adverb too is usually deemed to contribute to a negative evaluation. We notice also that the adverbs very and too collocate with polarity neutral adjectives, which constitute respectively $8 \%$ and $4 \%$ of their collocations, that is, those adjectives that are by virtue neither positive nor negative, and only the context decides their polarity.

In the next sub-sections, we investigate how the adverbs too and very affect the original sentiment polarity (positive, negative and neutral) of the adjectives they modify. We also compare the two adverbs along the way.

\section{Too and very + Neutral Adjectives}

Too and very are both amplifiers (Quirk et al 1985), which means they are both used to express degrees of increasing intensification upwards from an assumed norm. Nonetheless, the two adverbs are dissimilar. While very increases the intensity of the degree for the predicates, the adverb too not only increases the intensity of the degree, but under some conditions, it can add a negative evaluation. Consider:

(1a) The room is very large

(1b) The room is too large

In both of the above examples, the adverbs very and too amplify the intensity of degree for the adjective large. Nevertheless, only (1b) reveals a negative evaluation concerning the fact that The room is large, while (1a) shows a rather neutral opinion regarding the polarity such as positive or negative. This negative opinion expressed by too in (1b) is often neglected among scholars in linguistics, because it is different from 'negation adverbs', which formally introduce a negation on the positive sentences, or 'the adverbs known as NPIs', which formally require negative sentences: it simply adds a negative opinion which is not a semantic negation, but a pragmatic negative evaluation. 


\section{Too and Very + Positive and Negative Adjectives}

As mentioned before, the adverb too is usually considered as a negative intensifier regarding the degree of modified predicates, in opinion mining research as well as in linguistics literature. However, we demonstrate in this section that the adverb too is quite similar to the adverb to the adverb very in that they rather play the role of a booster in terms of Quirk et al. (1985), than a polarity reversing marker in terms of Kennedy \& Inkpen (2006), especially when associated with negative and positive which constitute together more than $90 \%$ of the adverbs' collocations in the BNC. Consider the following sentence:

(2) You are smart.

The above example comprises the adjectival predicate smart. Due to the semantic property of this adjective, the evaluation of the entity occurring in the subject position is positive. When the adverbs too and very are introduced to modify the adjective, they simply emphasize the original semantic property of the adjective as shown in the following examples:

(3) a. You are very smart.

(3) b. You are too smart.

In both sentences, the positive property of the adjective smart receives a stressed positive evaluation by means of the introduction of the adverbs too and very. Nevertheless, the two adverbs differs in terms of the degree of intensity in that too projects a stronger intensity than very. Consider the following example:

(4) a. The pay is very good for me $=$ I am satisfied with it.

(4) b. The pay is too good for me = it is more than what I qualify for.

The evaluation of the entity in the subject position (the pay) is clearly more positive in (4.b) than in (4.a). This is due to the higher intensifying property the adverb too has over the adverb very.

Similarly, the two adverbs too and very further intensify the negative semantic property of negative adjectives. Consider:

(5) a. The new computer is very expensive.

(5) b. The new computer is too expensive.

By all accounts, any entity modified by the adjective expensive would be assessed to have a negative sentiment polarity due to the negative semantic property inherited in the adjective expensive.

To sum up, the adverbs too and very do not change the sentiment polarity expressed by positive and negative adjectives, but simply emphasize their original meaning. Because positive and negative adjectives constitute more 
than $90 \%$ of the collocations of too and very, we believe these adverbs primarily work as meaning boosters at the expanse of a very shallow use of too with neutral adjectives (4\%), which has a subjective orientation rather being negatively oriented.

\section{Corpus Types}

After conducting a frequency search using the chart search option enabled by the BNC, the results we obtained are as follows:

Table 7. Frequency of Very According to Different Sections in the BNC

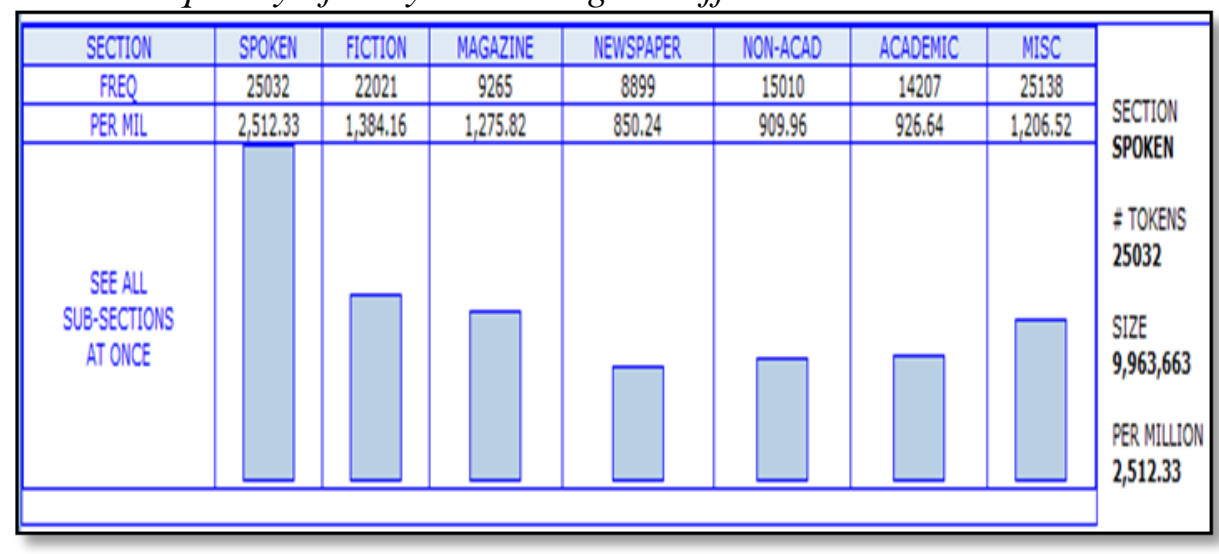

Table 8. Frequency of Too According to Different Sections in the BNC

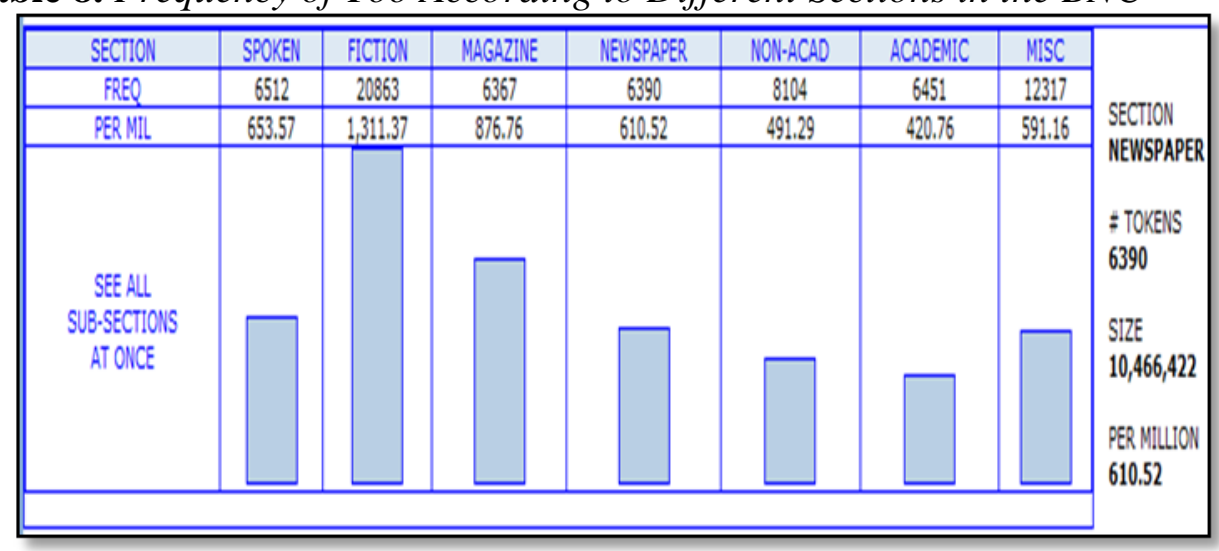

The two charts above allow us to see clearly the difference between the two adverbs in terms of the scope of their usage. The majority of the occurrences of the adverb very were found in the spoken section of the BNC followed by the fiction corpus type. On the contrary, the adverb too was highly used in the fiction, followed by magazine, and the spoken corpus type comes in the third place. This suggests that there is a difference of formality degree between both adverbs. Namely, very appears in less formal contexts than too. 


\section{Conclusion}

The adverbs too and very are generally known as intensifying a given meaning of modified words, notably adjectives and adverbs. However, based on the empirical examination of the British National Corpus (BNC), we assumed that the prominent sentiment polarity type of the words collocated with very is dissimilar to that of the words collocated with too. In most previous works, it is asserted that this is due to the particular semantic function of the adverb too. Nevertheless, we demonstrated that this interpretation does not result from the special function of too, but from the semantic orientation itself of the words collocated with these adverbs.

The experiment we performed in this study reveals that the adjectives of negative polarity co-occur with too 7 times more frequently than those of positive polarity. On the contrary, the adjectives of positive polarity co-occur with very 2.6 times more frequently than those of negative polarity. The distribution of part-of-speech in the position collocated with these adverbs, the proportion of words with positive/negative/neutral polarity and the corpus types such as formal/written texts or informal/spoken texts clearly deplore Biber's et al. (1999) assertion that adverbs like very and too are used interchangeably.

\section{References}

British National Corpus website: http://corpus.byu.edu/bnc/

Biber, D., Johansson, S., Leech, G., Conrad, S., \& Finegan, E. (1999). Longman grammar of spoken and written English. London: Longman.

Firth, J.R. (1957). 'A synopsis of linguistic theory 1930-1955' in F.R. Palmer (ed.) Selected Papers of J.R. Firth 1952-1959, Longman.

Graeme. K. (2003). 'Amplifier Collocations in the British National Corpus: Implications for English Language Teaching'. TESOL Quarterly Vol. 37, No. 3, pp. 467-487.

Greenbaum, S. (1974). 'Some verb-intensifier collocations in American and British English'. American Speech, 49, 79-89.

Kennedy, A., Inkpen, D., 2006. Sentiment Classification of Movie Reviews Using Contextual Valence Shifters. Computational Intelligence. Vol. 22. 110-125.

Mackin, R. (1978). 'On collocations: Words shall be known by the company they keep'. In P. Strevens (Ed.), In honour of A. S. Hornby (pp. 149-165). Oxford: Oxford University Press.

McCarthy, M. \& O'Dell, F. (2005). English collocations in use. Cambridge: Cambridge University Press.

Polanyi, L. and Zaenen, A. (2004). Contextual valence shifters. In Proceedings of AAAI Spring Symposium on Exploring Attitude and Affect in Text, pages 106111.

Quirk, Randolph, S. Greenbaum, G. Leech, and J. Svartvik. (1985). A comprehensive grammar of the English language. London: Longman

Sinclair, J. 1991. Corpus, concordance, collocation. Oxford: Oxford University Press. 
Vol. 1, No. $1 \quad$ Frej \& Nam: Sentiment Polarity Types of Collocations for too and very

Sun, Y.C., \& Wang, L. Y. (2003). 'Concordancers in the EFL classroom: Cognitive approaches and collocation difficulty'. Computer Assisted Language Learning, 16, 83-94.

Wouden, T. V. D. (1997). Negative contexts: Collocation, polarity and multiple negation. London: Routledge.

Xiao, R., \& McEnery, T. (2006). 'Collocation, semantic prosody, and near synonymy: A cross-linguistic perspective’. Applied Linguistics, 27, 103-129. 